\title{
Spider silk as mechanical lifeline
}

SIR - Here I look at the relationship between the mechanical properties of silk drag-lines and a spider's weight, to explain the measured values of the mechanical strength of drag-lines. Spider silks have been studied from the points of view of mechanical strength ${ }^{1-3}$, strain energy ${ }^{4}$, physico-chemical $^{5}$, thermal $^{6}$ and optical ${ }^{7}$ properties, and ageing ${ }^{8}$. There have been many estimates of breaking strength, elastic modulus ${ }^{9,10}$ and elongation from stress-strain curves. Mechanical strength has been explained at the molecular level and examined from the point of view of molecular orientation $^{11,12}$.

Drag-lines secreted from the spider's body are a tool for the animal to move, fall from trees, capture insects and build orb-webs, as well as to support her weight and keep her alive. It is well known that drag-lines are a lifeline for spiders, as these animals are often surrounded by danger. The mechanical strength of draglines may be related to the spider's weight because spiders hang from them, but, to my knowledge, there have been no reports detailing this relationship. I therefore considered the mechanical strength of the drag-line as a 'safety coefficient'. The spider's 400-million-year evolution should have allowed the mechanical properties of drag-lines to become maximally efficient.

It is important to know whether measured values of elastic-limit strength and breaking strength are meaningful as safety coefficients. A clear relationship between mechanical strength and spider weight would provide a basis for the safety coefficient - a measure of security, equivalent to that used in structures such as lifts,

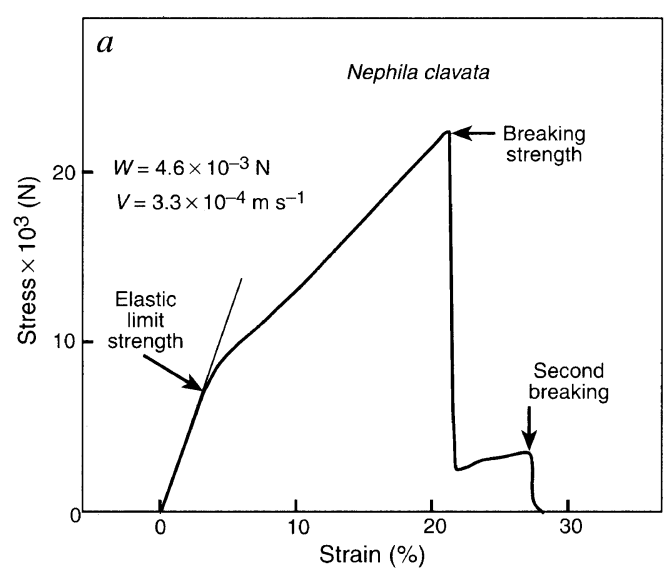

FIG. 1 a, Stress-strain curve for the drag-line of a spider ( $N$. clavata) with a weight of $4.6 \times 10^{-3} \mathrm{~N}$ at a stretching velocity of $3.3 \times 10^{-4} \mathrm{~m} \mathrm{~s}^{-1}$. Elastic-limit strength (ES) is defined as the stress at which the stress-strain curve alters from linear to nonlinear. Breaking strength (BS) is defined as the stress at the breaking point of drag-lines. $b, \mathrm{ES}$ and BS for $N$. clavata drag-lines plotted against $W$. Stretching velocity, $V$, is $3.3 \times 10^{-4} \mathrm{~m} \mathrm{~s}^{-1}$.

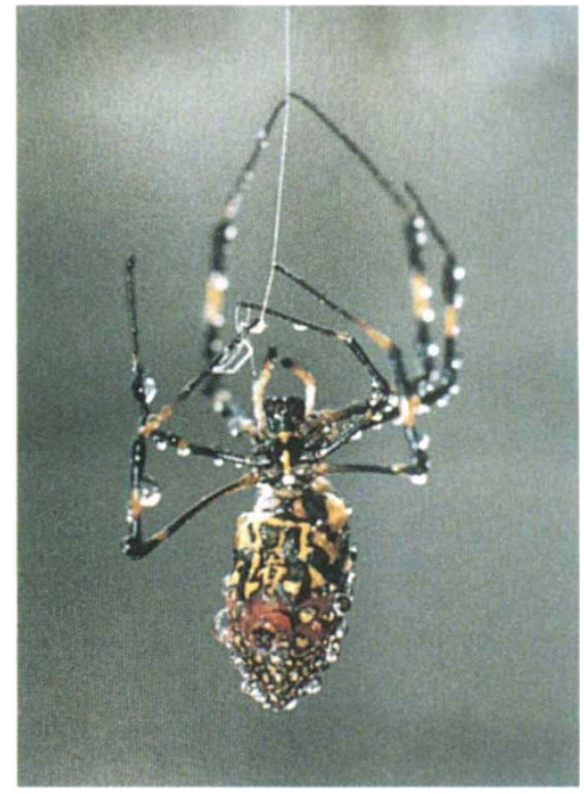

FIG. 2 Nephila clavata hanging from a silk drag-line.

drag-lines plotted against weight. The breaking strength increases linearly with increasing spider weight with a slope of about 6 . Thus, drag-lines should break at a stress equivalent to that produced by about six times the spider's weight.

Because spiders move, jump and fall rapidly, their life is surrounded with various dangers. In such circumstances, maximum efficiency is needed for the mechanical strength of drag-lines. The results described here provide an estimate of this efficiency.

\section{Shigeyoshi Osaki}

Department of Macromolecular Science, Shimane University,

Matsue, Shimane 690,

Japan

e-mail: s-osaki@edu.shimane-u.ac.jp

1. Denny, M. J. Exp. Biol. 65, 483-506 (1976).

2. Gosline, J. M. Denny, M. W. \& DeMond, M. E. Nature 309, 551-552 (1984).

3. Cunniff, P. M., Fossey, S. A., Auerbach, M. A. \& Song, J. W. Silk Polymers 234-251 (Am. Chem. Soc., Washington DC, 1995).

4. Brandwood, A. J. Exp. Biol. 116, 141-151 (1985).

5. Work, R. W. \& Morosoff, N. Text. Res. J. 46, 349-356 (1982).

6. Osaki, S. Acta Arachnol. 37, 69-75 (1989).

7. Osaki, S. Acta Arachnol. 38, 21-28 (1989).

8. Osaki, S. Acta Arachnol. 43, 1-4 (1994).

9. Termonia, Y. Macromolecules 27, 7378-7381 (1994).

10. Kaplan, D., Adams, W. W., Farmer, B. \& Viney, C. Silk Polymers 185-195 (Am. Chem. Soc., Washington DC, 1995).

11. Osaki, S. Nature 347, 132 (1990).

12. Simmons, A. H., Michal, C. A. \& Jelinski, L. W. Science 271, 84-87 (1996).

13. Lucas, F. Discovery 25, 20-26 (1964)

\section{Scientific Correspondence}

Scientific Correspondence is intended to provide a forum in which readers may raise points of a scientific character. Priority will be given to letters of fewer than 500 words and 10 references. 